\title{
THE EFFECT OF METHICILLIN ON SKIN LESIONS IN GUINEA-PIGS CAUSED BY "METHICILLIN-SENSITIVE" AND "METHICILLIN-RESISTANT" STAPHYLOCOCCUS AUREUS
}

\author{
J. H. HEwITT* AND P. J. SANDERSON $\dagger$ \\ Division of Hospital Infection, Clinical Research Centre, Harrow HAl 3UJ*, and Department \\ of Microbiology, Northwick Park Hospital, Harrow HAl $3 U J \dagger$
}

SINCE the introduction of penicillinase-stable penicillins there has been a steady increase in the reported frequency of strains of Staphylococcus aureus that show the temperature-dependent, heterogeneous resistance to all penicillins. and cephalosporins which is usually referred to as "methicillin resistance" (Parker and Hewitt, 1970). This resistance is often difficult to recognise in disk-diffusion tests with methicillin performed at $37^{\circ} \mathrm{C}$. Many strains give zones. of inhibition intermediate in size between those of clearly sensitive and clearly resistant strains, and may show colonies inside the main zone of inhibition when a heavy inoculum is used. Such strains are more easily recognised as. resistant if a lower incubation temperature is used, e.g., $30^{\circ} \mathrm{C}$ (Annear, 1968; Hewitt, Coe and Parker, 1969). Before this was realised, however, methicillin resistance was undoubtedly often overlooked, and it seems possible that many infections caused by resistant strains have been resolved without the true nature of the infecting organism becoming known (Smith, Hamilton-Miller and Knox, 1969).

Except for cases of septicaemia or bacteriaemia (Harding, 1963; Stewart and Holt, 1963; Bastin, Worms and Acar, 1967; Benner and Kayser, 1968; Siboni and Krogh, 1968; Chabbert, 1970), there are few reports of clinical failures when methicillin, cloxacillin or related penicillins and cephalosporins. were used alone for the treatment of infections caused by such strains. However, the reports of Turner and Cox (1967) and of Harris (1970), who used cloxacillin, suggest that methicillin resistance may be of clinical significance in some other types of infection. The persistence or "enrichment" of a highly resistant minority of the population of cells during methicillin, oxacillin, or cephalothin therapy has been reported (Chabbert et al., 1965; Bastin et al., 1967; Siboni and Krogh, 1968).

These observations, and those of Bulger, Feigl and Nielson (1972), which showed the persistence of this type of strain after 10 days of treatment with methicillin or cephalothin in an experimental renal infection in rats, indicate

Received 24 July 1973; accepted 29 Aug. 1973.

* Present address: Public Health Laboratory, Plymouth General Hospital, Plymouth PL4 8NN, Devon.

$\dagger$ Present address: Department of Microbiology, North Middlesex Hospital, Silver Street, London N18 1QX.

J. MED. MICROBIOL.-VOL. 7 (1974)

223

$\mathbf{P}$ 
that a fully bactericidal effect may be difficult to achieve in some situations when methicillin and related antibiotics are used alone.

Because these organisms are often isolated from patients with serious infections, it is clearly necessary to know under what conditions the resistance is of clinical significance. An attempt to obtain information on this aspect of the problem from the retrospective analysis of clinical case histories (Hewitt 1971) brought no response.

Model infections in laboratory animals are no substitute for clinical observation but may provide potentially useful information. We here describe some studies on the effectiveness of a single dose of intravenous methicillin on the development of intradermal staphylococcal infections in the guinea-pig, in which we used the experimental model of Miles, Miles and Burke (1957).

\section{MATERIALS AND METHODS}

Strains of Staphylococcus aureus. These were originally isolated from hospital patients. They were selected on the basis of their in-vitro sensitivity to methicillin in tube-dilution tests of MIC of the antibiotic. Each strain gave a similar dose-response relationship when the number of bacteria injected was plotted against lesion diameter (see below). The two methicillin-sensitive strains were (1) international bacteriophage-propagating strain no. PS80 (no. NCTC9789) which has the phage-typing pattern 80/81 and produces penicillinase, and (2) no. 72/025462, a benzylpenicillin-sensitive organism recently isolated from an abscess in a patient at Northwick Park Hospital, which is untypable with bacteriophage.

The two strains showing temperature-dependent resistance to methicillin were (1) no. 60/13136 (phage-typing patterns 7/47/53/54/75/77) which was from the same source as and is indistinguishable from no. 60/13137 (no. NCTC10442) referred to by Jevons (1961), Knox (1961), and others, and (2) strain no. 67/7270 (lysed by phage 29 at RTD $\times 1000$, and inhibited by group-III phages) used by Parker and Hewitt (1970). Both are typical of methicillin-resistant S. aureus strains found in British hospitals and both produce penicillinase. All the strains were maintained on nutrient agar slopes.

Determination of the MIC of methicillin. A broth-dilution technique with doubling dilutions of antibiotic in Oxoid Nutrient Broth No. 2 was used. Two inoculum sizes, c. $10^{3}$ and $10^{6}$ organisms per $\mathrm{ml}$ of antibiotic broth, were employed, and incubation was at $37^{\circ} \mathrm{C}$. The MIC was taken as the lowest concentration of antibotic that prevented visible growth after 18 hours' incubation. Each strain was tested in duplicate and the results are summarised in table I. The MIC for a methicillin-resistant strain determined by this method is greatly affected by several factors, including inoculum size, incubation temperature, the nature of the medium, and the duration of incubation. Variations in some or all of these can give results anywhere in the range $3 \cdot 12-500 \mu \mathrm{g}$ per ml. Strains fully sensitive to methicillin do not show such variability.

The sensitivity to methicillin (10- $\mu \mathrm{g}$ disks) and benzyl penicillin (2- $\mu \mathrm{g}$ disks) of each strain was checked regularly by diffusion tests and compared with the fully antibiotic-sensitive Oxford strain of $S$. aureus (no. NCTC6571).

Staphylococcal suspensions for injection. These were prepared from an overnight culture in $20 \mathrm{ml}$ of Todd-Hewitt Broth (Oxoid), which had been seeded from a freshly plated culture of each strain. The turbid broth cultures were centrifuged, the supernatants decanted, and the sedimented cells resuspended in $3 \mathrm{ml}$ of $0.85 \%(\mathrm{w} / \mathrm{v})$ sodium chloride containing $2.5 \%(\mathrm{v} / \mathrm{v})$ Todd-Hewitt broth. These are referred to as the saline-Todd-Hewitt suspensions. No other measures were taken to standardise the cultures, but in all the experiments the viable counts of the suspensions used for inoculation were determined by the method of Miles, Misra and Irwin (1938). It was found that the viable counts of suspensions kept at room temperature remained steady for 5 hours; in some experiments inoculations were made during a period of 4 hours from the same suspension. 
Animals. Female guinea-pigs of the albino Hartley strain were used. To allow for variation in response between animals, three were used in most treatment groups. In any one experiment the weight range of animals was normally within $\pm 40 \mathrm{~g}$ of the mean, though the mean weight ranged in different experiments from 400 to $670 \mathrm{~g}$.

The mean normal rectal temperature of the guinea-pig is quoted as $38.3^{\circ} \mathrm{C}$-range $37 \cdot 4-39 \cdot 4^{\circ} \mathrm{C}$ (Short and Woodnott, 1969), and as $39^{\circ}-40^{\circ} \mathrm{C}$ (Paterson, 1967). Differences in body temperature between men and experimental animals and over different parts of the body surface are factors that might influence the importance of the temperature-dependent resistance to methicillin in vivo.

Intradermal injections. The hair of the trunk region, dorsal to a line $3 \mathrm{~cm}$ on each side of the ventral mid-line, and of the posterior surface of the hind legs, was clipped and depilated as described by Miles et al. (1957). The bacterial suspensions were shaken before use; $0 \cdot 1 \mathrm{ml}$ was injected through a 26-gauge ( $\frac{3}{8}-\mathrm{in}$.) needle. Sixteen injections were usually made in each animal in a partly randomised pattern of sites.

Administration of methicillin. Immediately after the inoculation of staphylococci, sodium methicillin ("Celbenin", Beecham Research Laboratories), freshly dissolved in

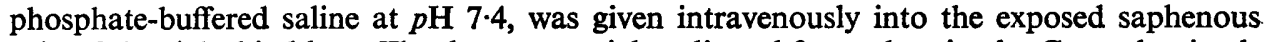
vein of the right hind leg. The dose was weight-adjusted for each animal. Control animals received only phosphate-buffered saline. The antibiotic-treated and the control animals. were subjected to the same procedure of vein cut-down to compensate for any shock that might affect the lesion (Miles et al., 1957). In later experiments the staphylococcal suspensions, and the antibiotic and control solutions, were coded in an attempt to read the results. under double-blind conditions.

Skin lesions. The diameter of the zone of induration at each inoculation site was measured approximately 24 hours after inoculation. The exact time of reading was not found to be critical. Under good illumination and with the skin relaxed the opposite margins of each lesion were marked and the diameter was measured with a ruler to the nearest halfmillimetre.

Lesion diameters were in the range $2-14 \mathrm{~mm}$; those less than $4 \mathrm{~mm}$ could not be certainly distinguished from trauma due to the injection. The zone of induration did not necessarily coincide with the zone of erythema, and the extent of necrosis was ignored.

Serum-antibiotic assays. In two separate groups of four and six animals, serum concentrations of methicillin after intravenous injection were determined by cup-plate assay. Blood was obtained by cardiac puncture as soon as possible (within 3-9 min.), and again 2 and 4 hours after administration of the drug. At least three replicates of each experimental sample and suitably chosen standard solutions were assayed. Methicillin concentrations. of as little as $1.0 \mu \mathrm{g}$ per $\mathrm{ml}$ were detectable by the assay system.

\section{RESULTS}

To compare in vivo the response of different strains of organisms to an antibiotic the findings have to be expressed in numerical terms. The effect observed in these experiments was on the size of the lesion. We had to establish therefore that this had a direct relationship to the dose of viable organisms injected and that this relationship was similar for each of the four strains used. For our purposes we defined "infectivity" as the change in the size of lesion that resulted from a 10 -fold change in the number of viable bacteria injected. Dilutions of the four strains were prepared in saline-Todd-Hewitt broth, as shown in fig. 1. A single intradermal injection of the three dilutions of all four strains was made in each of three animals. The lesions were measured after 24 hours and the averaged results plotted as shown. The mean values so plotted against the $\log _{10}$ dose gave the dose-response slope for each strain. Over the range of inocula used a near-linear relationship was found for the 
four strains selected for the therapeutic study. The value for the " infectivity" for each strain could be read from the graphs and these as well as the in-vitro sensitivity findings are given in table I. The similarity of the mean values for the infectivity of these four strains suggests that, for lesion sizes falling within the linear range of the graph, similar changes in lesion size are probably associated with corresponding changes in the number of viable micro-organisms present (e.g., after antibiotic treatment).

TABLE I

In-vitro sensitivity results and individual and mean values for the "infectivity" of the strains of Staphylococcus aureus

\begin{tabular}{|c|c|c|c|c|c|c|c|c|c|}
\hline \multirow{3}{*}{ Strain number } & \multirow{2}{*}{\multicolumn{2}{|c|}{$\begin{array}{c}\text { MIC of methicillin } \\
(\mu \mathrm{g} \text { per ml) with } \\
\text { inoculum size per ml of }\end{array}$}} & \multirow{3}{*}{$\begin{array}{c}\text { Inhibition zone } \\
\text { diameter (mm) } \\
\text { in disk-diffusion } \\
\text { test, } 37^{\circ} \mathrm{C}^{*}\end{array}$} & \multicolumn{6}{|c|}{ Infectivity (see text) } \\
\hline & & & & \multicolumn{5}{|c|}{ in experiment number } & \multirow{2}{*}{$\begin{array}{l}\text { mean } \\
\text { value }\end{array}$} \\
\hline & $10^{3}$ & $10^{6}$ & & 1 & III & IV & V & VI & \\
\hline $\begin{array}{l}\text { PS80 } \\
72 / 025462 \\
60 / 13136 \\
67 / 7270 \\
\text { NCTC6571 } \\
\text { (Oxford } \\
\text { staphylococcus) }\end{array}$ & $\begin{array}{c}1 \cdot 56-3 \cdot 12 \\
0 \cdot 39 \\
3 \cdot 12-6 \cdot 25 \\
3 \cdot 12-6 \cdot 25 \\
0 \cdot 78-1 \cdot 56\end{array}$ & $\begin{array}{c}1 \cdot 56 \\
0 \cdot 78 \\
12 \cdot 5-25 \\
12 \cdot 5-25 \\
1 \cdot 56\end{array}$ & $\begin{array}{c}20-22 \\
30 \\
15 \dagger \\
16 \\
26-30\end{array}$ & $\begin{array}{l}3 \cdot 3 \\
\dddot{3 \cdot 2} \\
3 \cdot 1 \\
\ldots\end{array}$ & $\begin{array}{l}3.6 \\
3.6 \\
3.8 \\
\ldots\end{array}$ & $\begin{array}{c}3 \cdot 6 \\
2.8 \\
2 \cdot 6 \\
\ldots\end{array}$ & $\begin{array}{l}3 \ddot{1} \\
\ldots \\
\cdots \\
\cdots\end{array}$ & $\begin{array}{r}3 \cdot 0 \\
3 \cdot 4 \\
4 \cdot 3 \\
\ldots \\
\ldots\end{array}$ & $\begin{array}{c}3 \cdot 4 \\
3 \cdot 3 \\
3 \cdot 5 \\
3 \cdot 2 \\
\cdots\end{array}$ \\
\hline
\end{tabular}

* Ten- $\mu \mathrm{g}$ methicillin disk diameter $7 \mathrm{~mm}$, confluent inoculum.

$\uparrow$ Colonies present within the main zone of inhibition.

Provided that inocula of sufficient size were used, lesions were produced in control and in antibiotic-treated animals that fell within the linear part of the dose-response graph. Because the slopes of the dose-response curves were similar for all the strains we felt that it was permissible to compare the effect of methicillin on the lesions produced by the four chosen strains with inocula of a single size. This enabled us to obtain many replicate results for each variable in experiments on quite a small number of animals with a single large inoculum-more than $10^{8}$ viable organisms per injection site.

\section{Injection of heat-killed staphylococci}

We confirmed that viability of the staphylococci was essential for the production of a significant lesion by comparing lesion size after the injection of $0.1 \mathrm{ml}$ of live and of heat-killed suspensions of the four test strains. The findings are shown in table II. Measurement below $4 \mathrm{~mm}$ is unreliable, but it was clear that the formation of the typical indurated lesions depended on the viability and probably the multiplication of staphylococci at the site of injection.

\section{Toxicity of methicillin}

We tested the toxicity of intravenous methicillin in guinea-pigs with doses of 14 and $140 \mathrm{mg}$ per $\mathrm{kg}$; in man the usual dosage is approximately $14.5 \mathrm{mg}$ 
per $\mathrm{kg}$ body weight. Each dose was given to three healthy animals. One of the three animals in the higher dosage group died 72 hours after the
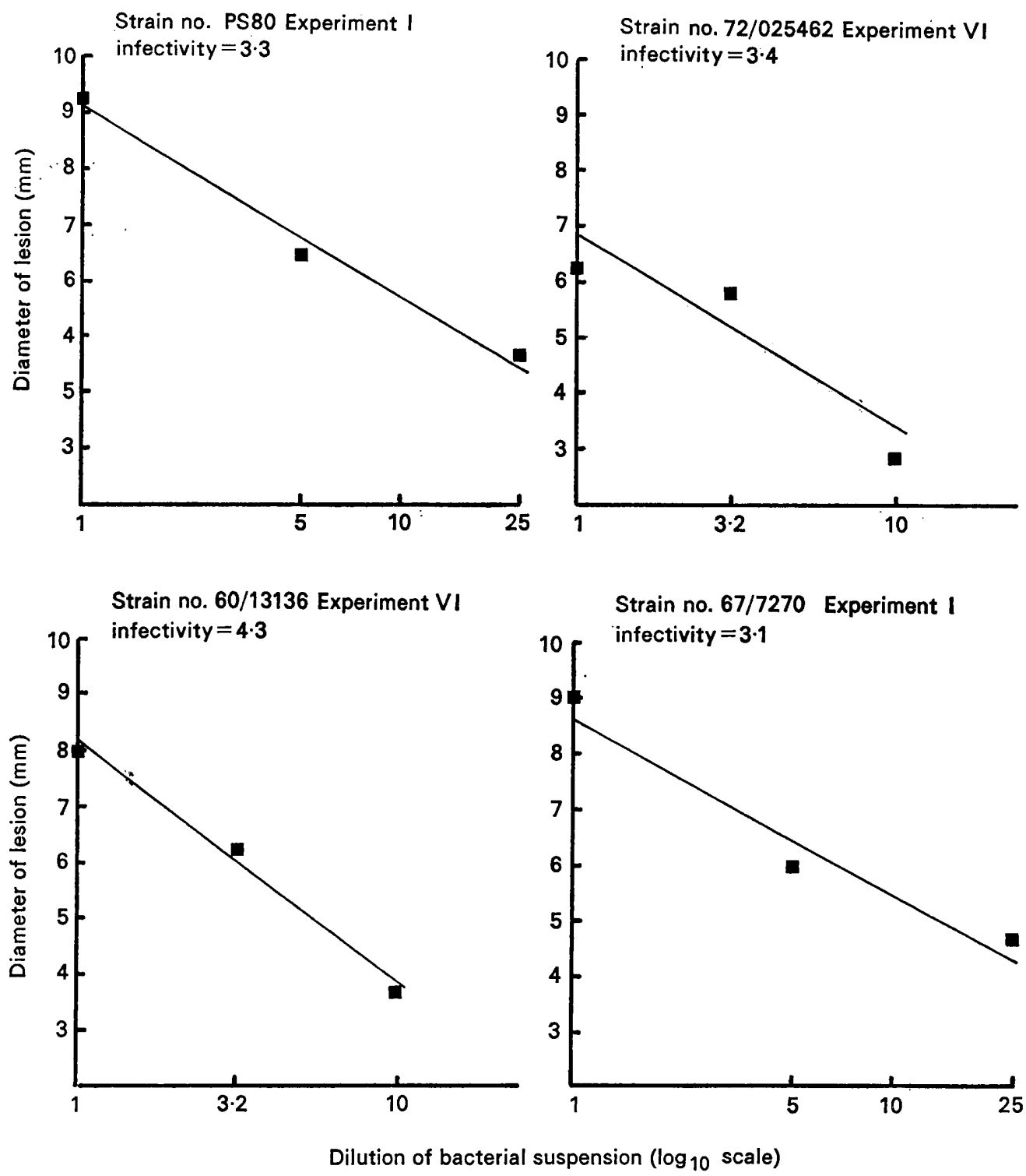

FIG. 1.-Representative determinations of the dose-response relationship for the four strains of Staphylococcus aureus. Infectivity is defined as the change in lesion diameter (mm) for a 10-fold change in inoculum size.

administration of methicillin. None of the other animals showed any evidence of drug toxicity within 7 days. These results suggested that there was little likelihood of toxicity in the dose-range, $1.56-100 \mathrm{mg}$ per $\mathrm{kg}$, that we wished to investigate. 
TABLE II

Correlation between viability of inoculum and lesion size

\begin{tabular}{l|ccc}
\hline \multirow{2}{*}{$\begin{array}{c}\text { Strain } \\
\text { number }\end{array}$} & $\begin{array}{c}\text { Viable count of } \\
\text { inoculum (in 0.1 ml) }\end{array}$ & \begin{tabular}{c} 
Mean lesion diameter (mm) with \\
\cline { 3 - 4 } vuspension
\end{tabular} & $\begin{array}{c}\text { heat-killed } \\
\text { suspension }\end{array}$ \\
\hline PS80 & $6.5 \times 10^{8}$ & 6.8 & 3.8 \\
$72 / 025462$ & $6.5 \times 10^{8}$ & 7.1 & 3.6 \\
$60 / 13136$ & $7.0 \times 10^{8}$ & 8.8 & 3.3 \\
$67 / 7270$ & $9.5 \times 10^{8}$ & 7.7 & 2.9 \\
\hline
\end{tabular}

\section{Therapeutic effect of methicillin}

We first compared lesions in a methicillin-treated group with those in an untreated control group. In later experiments we compared lesions in two different dosage treatment groups and a control group.

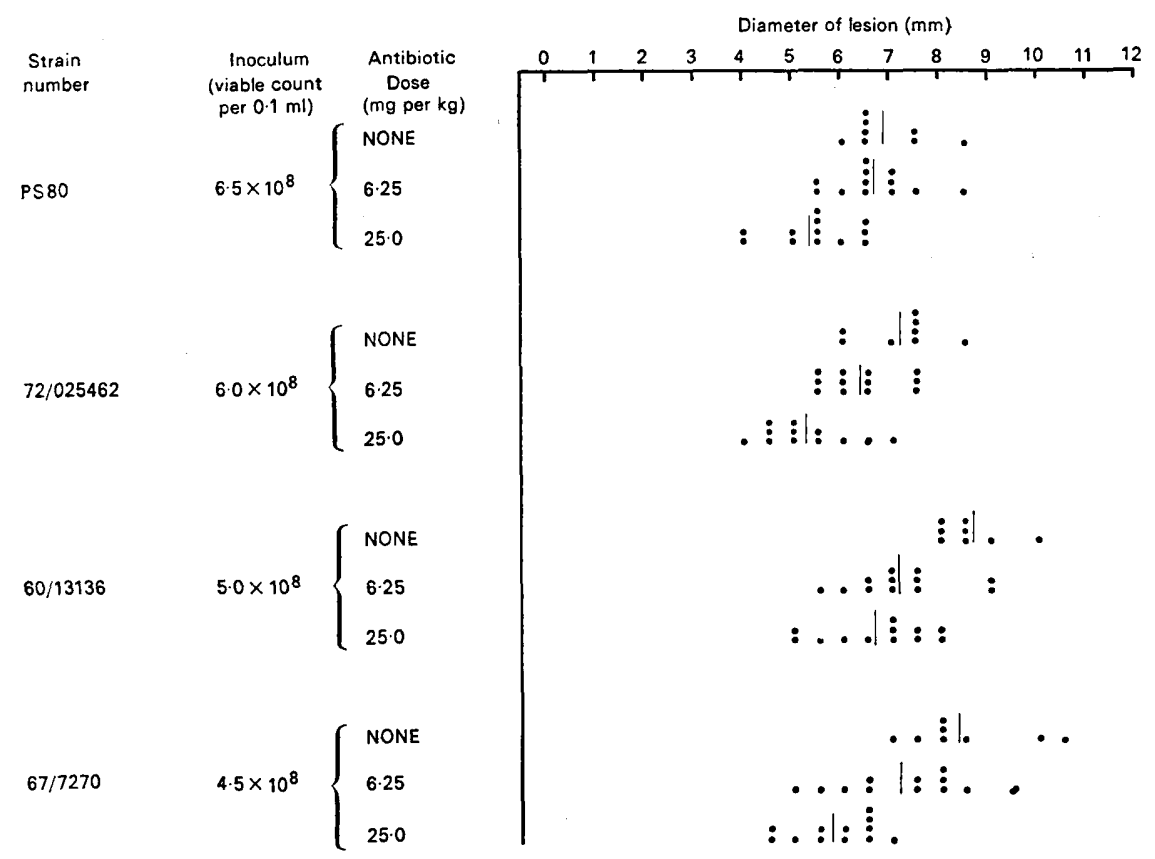

FIG. 2.-Effect of a single dose of methicillin, 6.25 or $25.0 \mathrm{mg}$ per $\mathrm{kg}$, on skin lesion size after intradermal injection of four strains of Staphylococcus aureus; $\bullet=$ individual values for lesion diameters; $\mid=$ mean value for a group of readings.

The results of one of the later experiments (no. IX), are shown in fig. 2 as an example. In this experiment we investigated the influence of 6.25 and $25.0 \mathrm{mg}$ per $\mathrm{kg}$ of methicillin on the development of the lesions. Each suspension was injected eight or, more usually, twelve times-four times in each of two or three animals. The values for each set of readings are shown in the figure. 
Table III summarises the results of all the experiments with different doses of methicillin; experiments at some dose levels were repeated. The mean viable counts of the inocula for the four strains were all in the range 3.9-6.0 $\times 10^{8}$ staphylococci per injection site; all counts were within the range $2 \cdot 0-7 \cdot 0 \times 10^{8}$. Doses of 25 and $100 \mathrm{mg}$ per $\mathrm{kg}$ of methicillin had similar effects on lesions caused by fully sensitive strains and by those showing the temperaturedependent resistance. At $12.5 \mathrm{mg}$ per $\mathrm{kg}$ or less, three out of five sets of

TABLE III

Influence of methicillin dosage on lesion size ( $\mathrm{mm}$ ) for four strains of Staphylococcus aureus

\begin{tabular}{|c|c|c|c|c|c|c|c|}
\hline \multirow{2}{*}{$\begin{array}{l}\text { Strains injected, and in-vitro } \\
\text { sensitivity to methicillin }\end{array}$} & \multicolumn{7}{|c|}{$\begin{array}{l}\text { Difference in mean lesion size }(\mathrm{mm}) * \text { between treated and } \\
\text { control animals with a dose of methicillin }(\mathrm{mg} \text { per } \mathrm{kg} \text { ) of }\end{array}$} \\
\hline & $\stackrel{1 \cdot 56}{(X I I) \dagger}$ & $\begin{array}{l}6 \cdot 25 \\
(\mathrm{IX})\end{array}$ & $\begin{array}{l}6 \cdot 25 \\
(\mathrm{X})\end{array}$ & $\begin{array}{c}12 \cdot 5 \\
(\text { VIII })\end{array}$ & $\begin{array}{l}12 \cdot 5 \\
(\mathrm{XII})\end{array}$ & $\begin{array}{l}25 \\
(\mathrm{IX})\end{array}$ & (VII) \\
\hline $\left.\begin{array}{l}\text { PS } 80 \\
72 / 025462\end{array}\right\}$ sensitive & $\begin{array}{r}0.0 \\
-0.6\end{array}$ & $\begin{array}{l}-0 \cdot 2 \\
-0 \cdot 8\end{array}$ & $\begin{array}{l}-1 \cdot 6 \\
-0 \cdot 4\end{array}$ & $\begin{array}{l}-1 \cdot 4 \\
-1 \cdot 3\end{array}$ & $\begin{array}{l}-1 \cdot 1 \\
-1 \cdot 5\end{array}$ & $\begin{array}{l}-1.4 \\
-1.9\end{array}$ & $\begin{array}{l}-3 \cdot 1 \\
-2 \cdot 3\end{array}$ \\
\hline $\left.\begin{array}{l}60 / 13136 \\
67 / 7270\end{array}\right\}^{\text {resistant }}$ & $\begin{array}{l}+0.6 \\
+0.4\end{array}$ & $\begin{array}{l}-1 \cdot 4 \\
-1 \cdot 2\end{array}$ & $\begin{array}{l}+0.4 \\
-1 \cdot 0\end{array}$ & $\begin{array}{l}-1 \cdot 3 \\
-1 \cdot 7\end{array}$ & $\begin{array}{l}-0 \cdot 4 \\
+0 \cdot 2\end{array}$ & $\begin{array}{l}-1 \cdot 9 \\
-2 \cdot 6\end{array}$ & $\begin{array}{l}-2 \cdot 6 \\
-3 \cdot 6\end{array}$ \\
\hline $\begin{array}{l}\text { Mean result: sensitive strains } \\
\text { Mean result: resistant strains }\end{array}$ & $\begin{array}{l}-0 \cdot 3 \\
+0.5\end{array}$ & $\begin{array}{l}-0 \cdot 5 \\
-1 \cdot 3\end{array}$ & $\begin{array}{l}-1 \cdot 0 \\
-0 \cdot 3\end{array}$ & $\begin{array}{l}-1.4 \\
-1.5\end{array}$ & $\begin{array}{l}-1 \cdot 3 \\
-0 \cdot 1\end{array}$ & $\begin{array}{l}-1 \cdot 7 \\
-2 \cdot 3\end{array}$ & $\begin{array}{l}-2 \cdot 7 \\
-3 \cdot 1\end{array}$ \\
\hline $\begin{array}{c}\text { Mean result for } \\
\text { each dose: }\end{array}\left\{\begin{array}{l}\text { sensitive strains } \\
\text { resistant strains }\end{array}\right.$ & $\begin{array}{l}-0.3 \\
+0.5\end{array}$ & $-c$ & & - & & $\begin{array}{l}-1 \cdot 7 \\
-2 \cdot 3\end{array}$ & $\begin{array}{l}-2 \cdot 7 \\
-3 \cdot 1\end{array}$ \\
\hline Mean for all four strains & $+0 \cdot 1$ & & & & & $-2 \cdot 0$ & $-2 \cdot 9$ \\
\hline
\end{tabular}

$*+=\mathrm{A}$ larger and $-=\mathrm{a}$ smaller lesion in the treated animals.

$\dagger$ Experiment number.

results showed some evidence of an effect in the anticipated direction, i.e., the two strains with the resistance showed less response to the antibiotic than the other two. The results with $1.56 \mathrm{mg}$ per $\mathrm{kg}$, in experiment XII, could be interpreted in this way, though there was a lack of response to the antibiotic with three out of four of the strains. Results of serum assays of antibiotic in guinea-pigs given this dose (see below), suggest that therapeutic concentrations (i.e., in excess of the MIC for fully sensitive staphylococci) were probably not attained in the serum or tissues.

It is of interest that the only strain to show a measurable response to methicillin therapy at $1.56 \mathrm{mg}$ per $\mathrm{kg}$ (strain no. 72/025462) was the one lacking penicillinase. Despite the relatively high stability of methicillin to staphylococcal penicillinase in comparison with benzylpenicillin, there is still a distinct possibility that penicillinase may be of some significance as an inactivator of methicillin, particularly where a concentration of staphylococcal cells producing large quantities of an extracellular penicillinase is encountered (Eriksen and Erichsen, 1964). We believe that the presence of penicillinase 
alone can account for a doubling of the tube-dilution MIC of methicillin for many hospital strains of Staph. aureus (Hewitt and Parker, 1968).

The duplicate sets of results shown for doses of 6.25 and $12.5 \mathrm{mg}$ per $\mathrm{kg}$ body weight indicate the extent of variation that may occur when this method

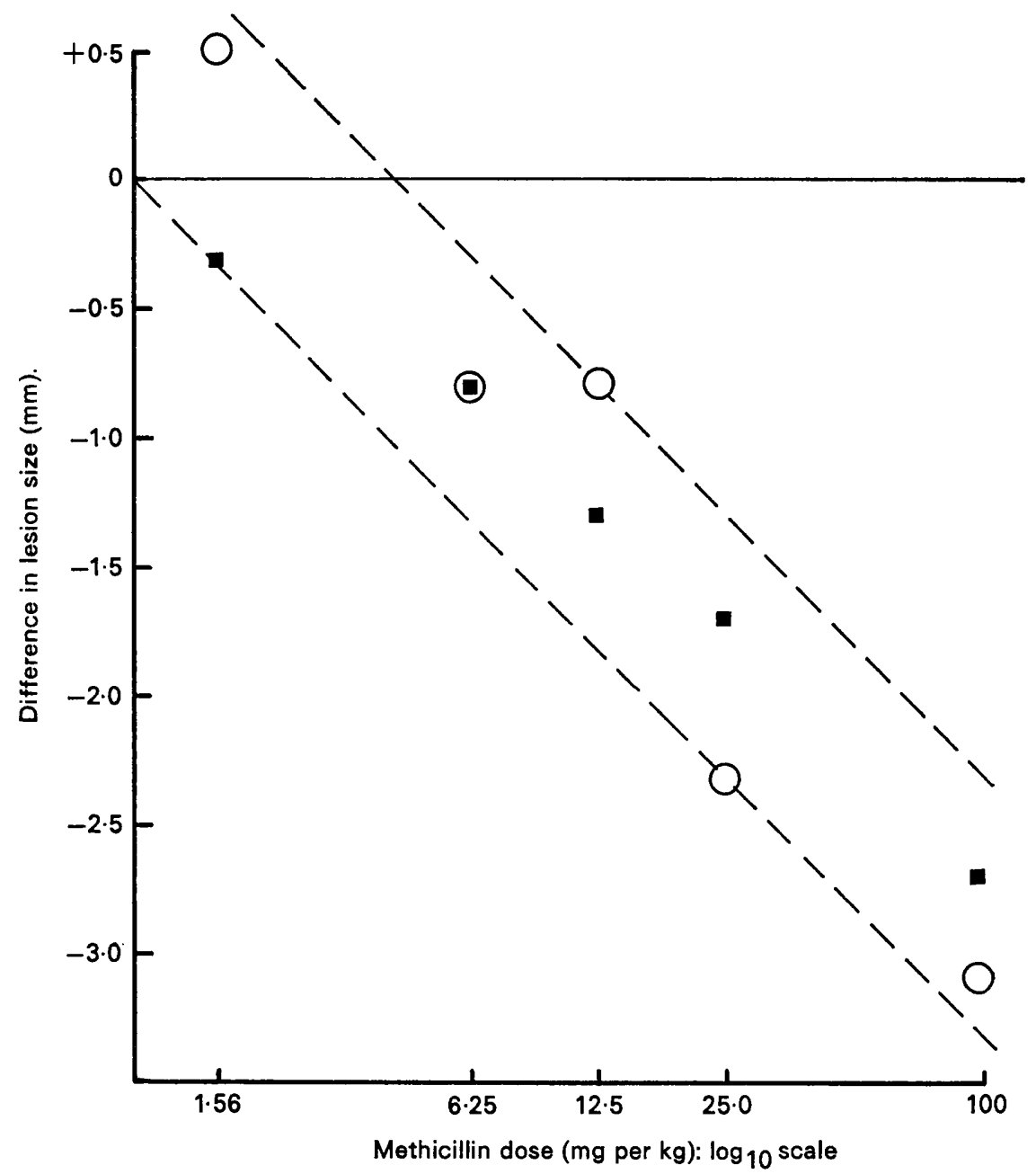

FIG. 3.-Mean difference in lesion diameter, in comparison with control animals, for each dose of methicillin used: $\square=$ mean difference for the two methicillin " sensitive " strains; $0=$ mean difference for the two methicillin "resistant" strains; - - = limits of the values observed.

is used. Too much reliance cannot be placed on the results of a single experiment, though the general trend is clear.

Fig. 3 shows the result of plotting the mean difference in lesion size for the two "sensitive" strains and for the two "resistant" strains against each dose investigated. There is a clearly marked linear dose-response relationship with both types of strains. We feel that the most appropriate interpretation is that the values for both types of strain fall within the same narrow band and that, although these strains showed a 2- to 16-fold difference in the MIC 
of methicillin it was not possible to discern a clear-cut difference in response, in this model, at any of the antibiotic dose-levels investigated.

\section{Assay of methicillin in serum}

Serum assays were performed to measure the blood concentrations attained and the rapidity of the distribution of the antibiotic into the tissues. After the intravenous administration of $1.56 \mathrm{mg}$ per $\mathrm{kg}$ the mean initial serum concentration was $2.4 \mu \mathrm{g}$ per $\mathrm{ml}$ (range 1.7-3.0); after a dose of $12.5 \mathrm{mg}$ per $\mathrm{kg}$ the mean initial concentration was $11.6 \mu \mathrm{g}$ per $\mathrm{ml}$ (range 6.9-18.8). In neither case was antibacterial activity detected in sera collected 2 or 4 hours after methicillin administration.

Assuming a plasma volume of $39 \mathrm{ml}$ per $\mathrm{kg}$ body weight in the guinea-pig (Ancill, 1956), the maximum theoretically attainable initial serum concentration on these doses would be $40 \mu \mathrm{g}$ per $\mathrm{ml}$ after $1.56 \mathrm{mg}$ per $\mathrm{kg}$ and $320 \mu \mathrm{g}$ per $\mathrm{ml}$ after $12.5 \mathrm{mg}$ per $\mathrm{kg}$. The low initial concentrations obtained, and the absence of activity after 2 hours suggest that there was a rapid loss of antibiotic from the serum into the tissues. This interpretation was supported by the observation that the serum concentrations of methicillin detected in blood taken from six animals between 3 and $6 \mathrm{~min}$. after the administration of $12.5 \mathrm{mg}$ per $\mathrm{kg}$ decreased from 19 to $7 \mu \mathrm{g}$ per $\mathrm{ml}$ as the time between administration and cardiac puncture increased. The data suggested that an equilibrium serum concentration of 8-10 $\mu \mathrm{g}$ per ml was established within $5 \mathrm{~min}$. of drug administration. Evenly distributed throughout the tissues, $12.5 \mathrm{mg}$ per $\mathrm{kg}$, would give a maximum tissue concentration of $12.5 \mu \mathrm{g}$ per $\mathrm{g}$. This concentration is well in excess of the in-vitro MIC of methicillin for sensitive staphylococci. It is probably in excess of the inhibitory concentration at $37^{\circ}-38^{\circ} \mathrm{C}$ for $99.9 \%$ of cells in most strains showing the temperature-dependent heterogeneous resistance. The heterogeneity in resistance to methicillin shown at $37^{\circ} \mathrm{C}$ by strain no. 60/13137 was described by Knox (1961), and by Sutherland and Rolinson (1964), and that of strain no. 67/7270 was documented by Parker and Hewitt (1970). The values for the MIC of methicillin for such strains when determined after 18 hours' incubation at $37^{\circ} \mathrm{C}$ with an inoculum of $10^{6}$ cells per $\mathrm{ml}$ typically fall within the range $6 \cdot 25-25 \cdot 0 \mu \mathrm{g}$ per $\mathrm{ml}$. When incubation at this temperature is prolonged the MIC value increases steadily due to the outgrowth of the more resistant cells.

We think that the doses of methicillin used in our experiments, which were comparable on a weight-for-weight basis to those used in man, probably achieved serum and tissue concentrations that were in the main below or around the MIC for the resistant strains as determined by conventional methods. With the possible exception of the concentrations that may have been obtained with a dose of $100 \mathrm{mg}$ per $\mathrm{kg}$, they were probably not greatly in excess of the MIC. Under these conditions any difference in response between the fully sensitive and heterogeneously resistant staphylococci should have been detectable.

The absence of antibacterial activity in sera collected 2 or more hours 
after antibiotic administration suggests that loss from the body by excretion was under way by this time. We do not know how long antibiotic may have persisted in the tissues.

\section{Discussion}

Although the dynamics of methicillin distribution and excretion in the body must depend on the dose and route of administration, we expected to be able to determine whether staphylococci of differing in-vitro sensitivity responded similarly to a single dose of antibiotic given intravenously. The use of this route ensured rapid and complete absorption and distribution of the antibiotic, well within the critical period of 2 hours after inoculation that is necessary for effective antibiotic activity in this experimental model (Burke, 1961).

In man, methicillin is normally administered by intramuscular injection every 4 or 6 hours. When $1.0 \mathrm{~g}$ was given to adults by this route, the peak concentrations in the sera collected half an hour after injection of the drug were in the range 8-27 $\mu \mathrm{g}$ per $\mathrm{ml}$, with a mean value of $18 \mu \mathrm{g}$ per ml (Knudsen and Rolinson, 1960). The serum concentration fell to a mean value below $1 \mu \mathrm{g}$ per $\mathrm{ml}$ within the next 4 hours. We consider that the equilibrium serum concentration of methicillin achieved in our guinea-pigs after intravenous administration of $12.5 \mathrm{mg}$ per $\mathrm{kg}$ was probably of the same order as that found in man after a $1.0 \mathrm{~g}$ intramuscular dose. It exceeded the MIC for fully sensitive strains and was within the range of MIC values for our " resistant" strains in tests performed at $37^{\circ} \mathrm{C}$.

At this dose we found no general difference in response between the in-vitro " sensitive " and " resistant " strains used. Strains showing the typical features of the temperature-dependent heterogeneous resistance to methicillin caused lesions that responded to methicillin treatment as judged by changes in lesion size. Neither was a difference in response seen with the lower doses of antibiotic used.

The magnitude of the response to a single dose of methicillin was closely related to the size of the dose of antibiotic, whether or not the strains showed " resistance". Whether a suitably chosen single or repeated dose of methicillin would yield a similar response in an established local infection in man is difficult to predict. The outcome would presumably depend on satisfactory penetration of antibiotic to the site of staphylococcal multiplication. There may already be information available on this situation from clinical observations, but it has not been published. Our experimental results suggest that in a localised lesion from which there is little risk of generalised septicaemic spread, methicillin or a related antibiotic at normal dosage may be as effective asif not more effective than--other agents for the control of a sufficient proportion of the staphylococcal population to give a significant therapeutic effect. This judgment is based on the observation of a diminution in lesion size, but we do not know whether complete eradication of the viable bacteria was achieved. For a rapid and complete bactericidal effect in serious infections caused by strains with this type of resistance it would still seem unwise to rely on 
methicillin or probably on any other penicillin or cephalosporin used alone. Much useful information on the clinical responsiveness of infections caused by these organisms to methicillin and cloxacillin therapy may have been overlooked because of a misunderstanding of the nature of this resistance, and also because of the rather loosely defined-indeed different-ways in which the word " resistance" is used.

It seems that there is also a lack of communication of clinical observations when, in a changing bacteriological situation, the most appropriate interpretation of in-vitro sensitivity tests is uncertain. When the clinical significance of any type of drug resistance is to be assessed there is need for all the information obtained by clinical experience and for in-vivo evaluation by treatment of experimental infections in animals. Reliance on in-vitro tests alone, such as the determination of the MIC, or on disk-diffusion inhibition-zone sizes and related measures of sensitivity may be an over-simplification, or they may even give misleading information. When in-vivo assessments are used, however, the conclusion that a strain may respond satisfactorily to an antibiotic in one situation does not mean that it will do so in another. This introduces an important factor into the choice and intrepretation of the most appropriate sensitivity tests for laboratory use.

On the present evidence we favour the use of the disk-diffusion test with methicillin at $30^{\circ} \mathrm{C}$ (Hewitt et al., 1969) for recognising all staphylococci with the temperature-dependent heterogeneous resistance. In addition to its epidemiological value, it has the advantage of picking out all strains that may give rise to serious, life-threatening infections for which intensive chemotherapy with antibiotics other than penicillins or cephalosporins is necessary. Sensitivity tests should at all times provide the maximum possible information about the specific type of drug resistance of a microbe, even though the choice of treatment-if any is indeed needed-may subsequently depend more on the nature of the lesion and general state of health of the patient than on the apparent outcome of the test. This is not to say that the sensitivity test is irrelevant, but that the nature of the micro-organism is only one of many aspects of any particular clinical situation, albeit one of the more readily determined aspects, that can influence the response of an infection to a particular chemotherapeutic agent.

Additional note. In an experiment on the influence of a single intravenous dose of neomycin sulphate $(1.56 \mathrm{mg}$ per $\mathrm{kg}$ ) on guinea-pig lesions caused by the same four strains of staphylococci, there was a marked difference in response with the three neomycin-sensitive strains (diminution of mean lesion diameter of 1.4-1.8 mm) in comparison with the response of the single strain that was neomycin resistant as judged by a disk-diffusion test-no. 67/7270 -in which the mean lesion-diameter was $0.5 \mathrm{~mm}$ larger in treated animals than in the controls. This result, although an isolated example, provides some supporting evidence that a difference in response between in-vitro sensitive and resistant strains can be detected, with some types of drug resistance, by means of this experimental model.

\section{SUMMARY}

The therapeutic effect of methicillin on skin lesions in guinea-pigs produced by two strains of Staphylococcus aureus showing heterogeneous resistance to 
methicillin, and by two strains of normal sensitivity, was compared. Methicillin was given intravenously immediately after the intradermal inoculation of staphylococci and the skin lesions were measured 24 hours later. The serum concentrations of methicillin were comparable to those obtained in man with standard dosage and were below or similar to the MIC of the " resistant" staphylococci when this was determined at $37^{\circ} \mathrm{C}$. No difference was found after methicillin administration in the size of lesions produced by " resistant" and "sensitive" staphylococci.

We wish to thank the following members of staff of the Clinical Research Centre and Northwick Park Hospital for their assistance: Miss Janet Rigby for technical assistance; Sir Ashley Miles for introducing us to the experimental method and for numerous helpful discussions; Dr Charles Coid and his staff in the CRC Animal Division for the provision of animal-house facilities; Mrs Zulekha Ismail for preparation of the typescript; and Dr Robert Blowers for his interest and encouragement.

\section{REFERENCES}

ANCill, R. J. 1956. The blood volume of the normal guinea-pig. J. Physiol., 132, 469.

ANNEAR, D. I. 1968. The effect of temperature on resistance of Staphylococcus aureus to methicillin and some other antibiotics. Med. J. Aust., 1, 444.

Bastin, R., Worms, R. AND ACAR, J. F. 1967. Traduction clinique de la résistance hétérogène des staphylocoques aux pénicillines et céphalosporines. Path. Biol., Paris, 15, 1205.

BENNER, E. J. AND KAYSER, F. H. 1968. Growing clinical significance of methicillinresistant Staphylococcus aureus. Lancet, $2,741$.

Bulger, R. J., Feigl, P. AND Nielson, K. 1972. Comparison of treatments with several antibiotics in experimental infections due to methicillin-resistant Staphylococcus aureus. J. infect. Dis., 126, 674.

BURKE, J. 1961. The effective period of preventive antibiotic action in experimental incisions and dermal lesions. Surgery, St Louis, 50, 161.

Chabbert, Y. A. 1970. Detection of methicillin and cephalothin resistant staphylococci. In The control of chemotherapy, edited by P. J. Watt, London, p. 17.

Chabbert, Y. A., Baudens, J. G., Acar, J. F. and Gerbaud, G. R. 1965. La résistance naturelle des staphylocoques à la méthicilline et l'oxacilline. Revue fr. Étud. clin. Biol., 10, 495.

ERIKSEN, K. R. AND ERICHSEN, I. 1964. Resistance to methicillin, isoxazolyl penicillins and cephalothin in Staphylococcus aureus. Acta path. microbiol. scand, 62, 255.

HARDING, J. W. 1963. Infections due to methicillin-resistant strains of Staphylococcus pyogenes. J. clin. Path., 16, 268.

HaRRIS, D. M. 1970. Clinical implications of methicillin-resistance in Staphylococcus aureus. Guy's Hosp. Rep., 119, 145.

HewITT, J. H. 1971. Antibiotic sensitivity testing. Br. med. J., 2, 248.

Hewitr, J. H., COE, A. W. AND PARKer, M. T. 1969. The detection of methicillin resistance in Staphylococcus aureus. J. med. Microbiol., $2,443$.

HewitT, J. H. AND PARKer, M. T. 1968. Sensitivity of penicillinase-forming strains of Staphylococcus aureus and of their penicillinase-negative variants to cephaloridine, cephalothin, methicillin, and benzylpenicillin. J. clin. Path., 21, 75.

Jevons, M. P. 1961. "Celbenin "-resistant Staphylococci. Br. med. J., 1, 124.

KNOX, R. 1961. “ Celbenin "-resistant Staphylococci. Br. med. J., 1, 126.

KNudsen, E. T. AND Rolinson, G. N. 1960. Absorption and excretion of a new antibiotic (BRL 1241). Br. med.J., 2, 700.

Miles, A. A., Miles, E. M. AND Burke, J. 1957. The value and duration of defence reactions of the skin to the primary lodgement of bacteria. Br. J. exp. Path., 38, 79. 
Miles, A. A., Misra, S. S. And Irwin, J. O. 1938. The estimation of the bactericidal power of the blood. J. Hyg., Camb., 38, 732.

Parker, M. T. AND HewitT, J. H. 1970. Methicillin resistance in Staphylococcus aureus. Lancet, 1, 800.

Paterson, J. S. 1967. In Universities Federation for Animal Welfare: handbook on the care and management of laboratory animals, 3rd ed., London, p. 241.

Short, D. J. AND WoodnotT, D. P. (EDitors) 1969. Institute of Animal Technicians: Manual of laboratory animal practice and techniques, 2nd ed., London, p. 71.

SIBONI, K. AND KROGH, L. 1968. The sensitivity to methicillin and penicillin of methicillinresistant strains of Staphylococcus aureus. Acta path. microbiol. scand, 74, 381.

Smith, J. T., Hamilton-Miller, J. M. T. AND KnOX, R. 1969. Bacterial resistance to penicillins and cephalosporins, J. Pharm. Pharmac., 21, 337.

Stewart, G. T. AND Holt, R. J. 1963. Evolution of natural resistance to the newer penicillins. Br. med. J., $1,308$.

SUtherland, R. AND Rolinson, G. N. 1964. Characteristics of methicillin-resistant staphylococci. J. Bact., 87, 887.

Turner, G. C. AND Cox, P. E. 1967. Resistance to cloxacillin among hospital staphylococci. J. clin. Path., 20, 870. 